\title{
Approach to the A-B Ring System of Forskolin through Biotransformation of Toluene
}

\section{Schapiro, G. Seoane and G. García}

Cátedra de Química Orgánica, Facultad de Química, Gral. Flores 2124, Universidad de la República, Montevideo, Uruguay

E-mail: vschapir@bilbo.edu.uy

\begin{abstract}
In the present work, we will intend to show that diol I, microbially derived from toluene using Pseudomonas putida 39D, is a suitable synthon for the synthesis of the A-B ring system of forskolin. The functionalization of diol $\mathbf{I}$, to be used as ring-B, and the attempts of ring-A closure, will be disclosed.
\end{abstract}

\section{Introduction}

Chiral cyclohexadiendiols of the type of $\mathbf{I}$, produced by microbial oxidation of arenes, have been extensively used as starting materials for the enantioselective synthesis of natural products. In this work, we present an approach to the synthesis of forskolin, based in a transfer of chirality from the homochiral diol I to the B ring of the diterpene, as shown in the retrosynthetic analysis.

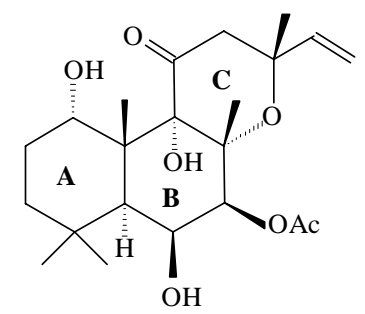

Forskolin

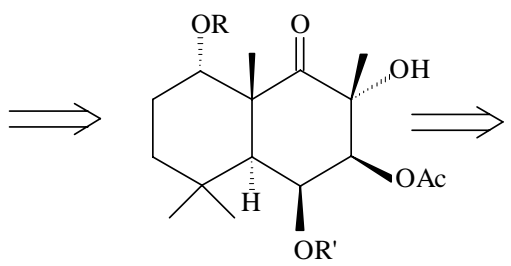

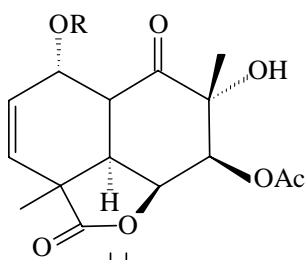<smiles>C=CC(O)C1C(C)=CC=CC1O</smiles><smiles>C=CO[C@H]1[C@@H](O)C=CC(=O)[C@]1(C)O</smiles>

II<smiles>C=CC=CC(=O)OC1C=CC(=O)[C@](C)(O)[C@@H]1OC(C)=O</smiles>

III 


\section{Experimental}

We will present the optimization of the synthetic route to obtain a structure of type II, via oxidation reactions and selective protection-deprotection sequences of the hydroxyl groups. We will also present the synthetic approaches to an structure of type III which allows the ring A closure through an intramolecular Diels-Alder reaction. We will also discuss the attempts to close ring A using an intermolecular Diels-Alder cycloaddition, studying the viability of the reaction with different dienes and experimental conditions.

\section{Results and Discussion}

We have synthesized enone $\mathbf{I V}$, as a model to study the intramolecular Diels-Alder reaction. To date, results have shown serious difficulties in terms of reactivity and stability of the model molecule. That's why we are trying different intermolecular cyclizations with molecules of type $\mathbf{V}$, utilizing more reactive dienes.<smiles>C/C=C/C=C/C(=O)O[C@H]1C=CC(=O)[C@@](C)(O)[C@@H]1O</smiles>

IV<smiles>CCO[C@H]1C=CC(=O)[C@@](C)(O)[C@@H]1O</smiles>

V

\section{$\mathbf{R}=\mathbf{H}, \mathbf{A c}, \mathbf{M O M}$}

$\mathbf{R}^{\prime}=\mathbf{H}, \mathrm{THS}, \mathbf{A c}$

Acknowledgments: CSIC, PEDECIBA, CONICYT.

\section{References and Notes}

1. Gibson, D.; Hensley, M.; Mabry, T. Biochemistry 1970, 9, 1926.

2. Hudlicky, T.; et al. Chem.Rev. 1996, 1195.

3. Seoane, G.; Brovetto, M.; Schapiro, V.; Cavalli, G.; Sierra, A.; Padilla P. New Journal of Chemistry 1999, 23, 549-556. 